\title{
Reassessment of the oldest British turtle: Protochelys from the Middle Jurassic Stonesfield Slate of Stonesfield, Oxfordshire, UK
}

\author{
Jérémy Anquetin1*, Julien Claude²
}

1Department of Palaeontology, The Natural History Museum, Cromwell Road, London SW7 5BD, UK

2Institut des Sciences de l'Évolution de Montpellier, UMR 5554 CNRS, Université de Montpellier 2, 34095 Montpellier cedex 5, France

*Corresponding author: jeremy.anquetin@jurassica.ch

\begin{abstract}
Protochelys Lydekker, 1889 from the Stonesfield Slate (middle Bathonian) is the oldest British turtle and the only record to date of fossil epidermal shell scales preserved isolated from underlying bone. Although known since the 1840s, these remains have never been properly described, figured or compared with other taxa. Here, we provide a thorough reassessment of the available material with a discussion of the exceptional preservation of isolated scales. We conclude that: (1) no satisfactory diagnosis can be proposed and Protochelys blakii has to be considered nomen dubium; (2) the carapace of the Stonesfield turtle has a plesiomorphic morphology (vertebral scales twice as wide as long; fifth vertebral scale as wide anteriorly as it is posteriorly; pleural scales longer than wide) shared with numerous basal turtles. The fossilisation of turtle epidermal scales is extremely rare (only two other examples are known). The Stonesfield material is unique in that the scales are isolated, without underlying bone. A review of the literature shows that isolation of shell scales occurs as a result of two processes: shedding of old scale layers during growth or post mortem disarticulation. We favour the disarticulation hypothesis because complete scales are thicker and more likely to preserve the well-developed ornamentation shown by the Stonesfield scales.
\end{abstract}




\section{Introduction}

The Stonesfield Slate is well known as the type locality of the first scientifically described dinosaur, Megalosaurus (Buckland 1824). This is also one of the richest Middle Jurassic terrestrial reptile localities in Great Britain (Evans \& Milner 1994; Benton \& Spencer 1995). Although most of the taxa from Stonesfield have been well studied, the fact that the Stonesfield Slate has yielded the oldest known British turtle is often overlooked.

Owen (1842: 160) was the first to notice impressions of turtle epidermal scales from the Stonesfield Slate. Blake (1863) confirmed the chelonian nature of these impressions and provided a short general description based on specimens in the British Museum (now housed in the Natural History Museum), without indicating which ones he had in hand. In the same issue of The Geologist, Mackie (1863) described an isolated coracoid from this locality that he attributed to a new species, Chelys(?) blakii. Later, Phillips (1871: 182) proposed the new species Testudo stricklandi for epidermal scales from the Stonesfield Slate housed at the Oxford University Museum. In his Catalogue of Fossil Reptilia and Amphibia, Lydekker (1889: 220) coined the new genus name Protochelys for $T$. stricklandi and provisionally referred the isolated coracoid described by Mackie (1863) to this form (although he did not change $P$. stricklandi to $P$. blakii as he should have according to the Principle of Priority). Few authors mention this material in the 20th Century. Romer (1956, 1966) and Bergounioux (1955) list Protochelys, which they tentatively assign to the Pleurosternidae, but do not discuss it. Evans \& Milner (1994) include Protochelys in their account of the Middle Jurassic microvertebrate assemblages from the British Isles without reassessing the material. Benton \& Spencer (1995) also mention the turtle from Stonesfield, but cast doubt on the chelonian affinities of the scale impressions.

Since Lydekker (1889), the turtle material from the Stonesfield Slate has been completely overlooked. Moreover, this material has never been properly described or compared, despite that turtles are extremely rare in Middle Jurassic deposits. The purpose of this paper is to reassess the available material of Protochelys in order to clarify the taxonomic status and possible affinities of this turtle. The remains are herein described and compared for the first time and a tentative reconstruction of the carapace is proposed. Moreover, the Stonesfield scales are an example of exceptional fossilisation and, consequently, are worthy of a detailed taphonomic discussion.

\section{Abbreviations}

BMNH, The Natural History Museum, London, UK
OUMNH, Oxford University Museum of Natural History, Oxford, UK.

\section{Geological settings}

The Stonesfield Slate was extracted from a localised series of mines and quarries that lie within a kilometre of the village of Stonesfield, Oxfordshire, England (Boneham \& Wyatt 1993: fig. 1). The slates were exploited as roofing stones (tiles) between the 17th and the early 20th Centuries (Aston 1974). The Stonesfield Slate consists of fine, calcareous sandstones and siltstones that are locally interbedded with thin and fissile laminae of ooliths (Boneham \& Wyatt 1993). The Stonesfield Slate was previously considered to be a member of the Taynton Limestone Formation or the underlying Sharp's Hill Formation. More recently, Boneham \& Wyatt (1993) demonstrated that the Stonesfield Slate represents a sporadic, recurrent lithofacies of the Taynton Limestone Formation. Based on the ammonite fauna, both the Taynton Limestone Formation and the Stonesfield Slate are referred to the Procerites progracilis Biozone, which corresponds to the lower part of the middle Bathonian (Torrens 1980; Boneham \& Wyatt 1993). Turtle remains are also known from other British Bathonian localities, especially Kirtlington and Cladach a'Ghlinne (Gillham 1994; Evans et al. 2006; Anquetin 2007; Scheyer \& Anquetin 2008), but these localities are late Bathonian in age (Evans \& Milner 1994).

The Stonesfield Slate has yielded a mixed assemblage of marine and terrestrial taxa: marine invertebrates (ammonites, belemnites, bivalves, gastropods, crustaceans, etc.), terrestrial plants, insects, fish, marine and terrestrial reptiles, and mammals (Evans \& Milner 1994; Benton \& Spencer 1995). This association suggests a deposit in a shallow inshore marine environment. Stonesfield quickly became famous with the discovery of fossil mammals and reptiles. Mammals are represented by two small jaws, of two different species, discovered in 1812 which are still the oldest unquestionable crowngroup mammals (Rowe 1999). Reptiles include marine crocodiles (steneosaurids), plesiosaurs, ichthyosaurs, pterosaurs (rhamphorhynchoids), dinosaurs (including the famous Megalosaurus), and turtles (Evans \& Milner 1994; Benton \& Spencer 1995). Fossil vertebrates occur in the three different lithofacies of the Stonesfield Slate (sandstones, siltstones and oolith laminae), without particular differences in faunal composition. The bone preservation is generally good but the material is disarticulated and was probably transported a short distance (Benton \& Spencer 1995). However, the presence of well preserved fragile elements like turtle epidermal scales (see below) and terrestrial plants suggests that 
scales (see below) and terrestrial plants suggests that transport was gentle.

\section{Material}

Apart from two isolated bones (a coracoid and a plastron fragment), all of the Stonesfield turtle specimens consist of unassociated, isolated carapacial scales (no plastral scale has been identified). The Stonesfield scales are unique in being the first isolated fossil turtle scales known to date (see Discussion). Interestingly, these scales are not imprints, as described by 19th Century authors, but thin fossilised layers picked out by iron staining or other mineralizations, in the same way as the majority of terrestrial plant remains from the same locality (Cleal \& Rees 2003). Palaeobotanists use the term 'impression' or 'compression-impression' to designate this type of preservation (Shute \& Cleal 1987; Cleal \& Rees 2003). At Stonesfield, turtle scales are often represented by an association ( 2 slabs) of the fossil scale itself (representing the original morphology of the scale; i.e., growth rings are thin grooves) and an external mould (representing a mould of the external surface of the scale; i.e., growth rings are low ridges). The nomenclature for shell elements follows Zangerl (1969).

Turtle shell scales usually possess growth rings (or growth annuli), though these are not always well pronounced. Generally, these rings indicate that growth was not equal in all directions. For carapacial scales mediolateral growth is faster laterally (or medially for marginals), whereas anteroposterior growth is faster anteriorly. This heterogeneous growth is common among turtles and allows isolated scales to be orientated. We used this characteristic to orientate the Stonesfield carapacial scales: the embryonic scale is at the posteromedial corner of the scale, except for marginals for which it is generally at the posterolateral corner of the scale.

\section{Systematic palaeontology}

Testudinata Klein, 1760 (sensu Joyce et al. 2004)

Protochelys blakii (Mackie, 1863) nomen dubium

Chelys(?) blakii Mackie, 1863: 41, fig. 1 (original description).

Testudo stricklandi Phillips, 1871: 182, diagram 41 (original description).

Protochelys stricklandi (Phillips): Lydekker, 1889: 220 (new combination).
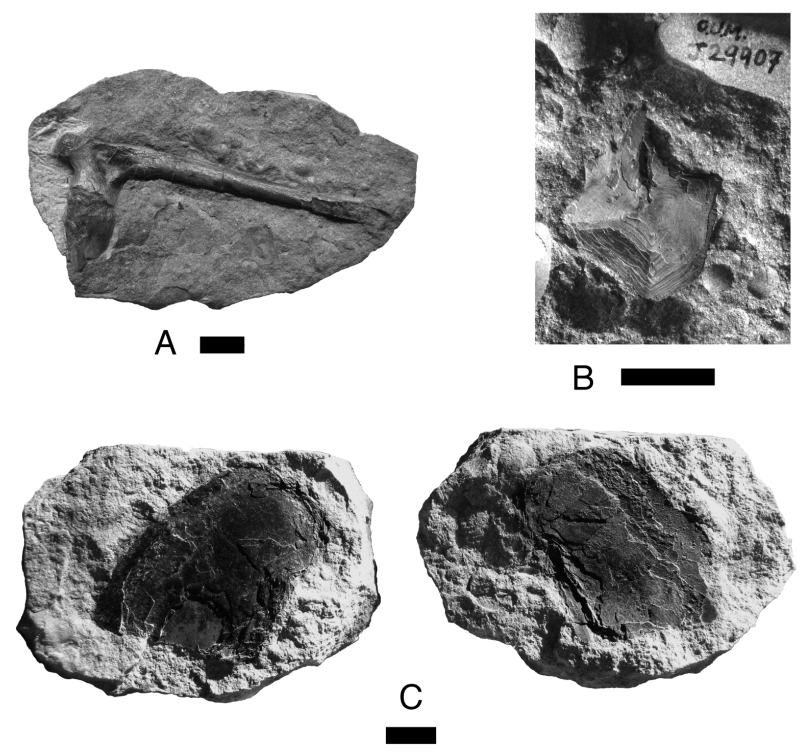

Figure 1 - Specimens from the Stonesfield Slate misidentified as chelonian. A, BMNH R896, specimen identified by Lydekker (1889: 222) as a "scapulo-precoracoid", but more probably an archosaur cervical rib; B, OUMNH J29907, a fish scale labelled as a turtle scale; C, OUMNH unnumbered, specimen ( 2 slabs) labelled as a turtle bony plate which consists of a splinter of compact bone probably from a crocodilian osteoderm. Scale bars: $10 \mathrm{~mm}$.

Holotype. - BMNH 37979; an isolated, slightly crushed right coracoid (figured in Mackie 1863) [holotype by monotypy].

Referred specimens. - BMNH 37218, complete vertebral (2 slabs); BMNH 37218a, complete vertebral; BMNH R247, half vertebral (2 slabs); BMNH R247a, half vertebral; BMNH 37218b, almost complete vertebral (due to a misreading of the original labelling, the external mould has been erroneously numbered BMNH 39198b after Lydekker (1889); the correct number is used herein); BMNH R247b, complete pleural (2 slabs); BMNH 39198, external mould of a pleural; BMNH 39198a, external mould of a small incomplete scale; BMNH R5320, isolated fragment of plastron; OUMNH J40407, complete vertebral; OUMNH J37067, complete small vertebral; OUMNH $\mathbf{3 7 7 3 7 5}$ + J77376, complete vertebral (2 slabs, both figured in Phillips 1871); OUMNH J77377, external mould of a small vertebral; OUMNH J77378, external mould of a half vertebral.

Horizon and age. - Stonesfield Slate, Taynton Limestone Formation, Stonesfield, Oxfordshire, England. The Stonesfield Slate is attributed to the lower part of the middle Bathonian (Torrens 1980; Boneham \& Wyatt 1993).

Remarks. - Due to the nature of the specimens, no satisfactory diagnostic characters can be identified. 
Comparisons with other taxa are also limited (see below). At least as far as the scales are concerned, the consistency of the morphology and preservation suggests that they only represent one taxon. There is no support for the separation of two taxa (one based on the coracoid, the other on the scales) and this would not improve the current taxonomic situation. So, it is sensible to treat all the remains as one species, which affinities are unknown.

Lydekker (1889: 222) referred to Protochelys the specimen BMNH R896 (Fig. 1A), which he interpreted as a "chelonian scapulo-precoracoid". In fact, this specimen is not chelonian. It shows pneumatic features and may be interpreted as a possible archosaur cervical rib. The collections of the OUMNH also contain several other specimens misidentified as chelonian: OUMNH J29907 (a fish scale; Fig. 1B) and an unnumbered specimen that consists of a splinter of compact bone (maybe from the base of a crocodilian osteoderm; Fig. 1C).

\section{Description}

\section{Coracoid}

BMNH 37979, as identified by Carter Blake in Mackie (1863), is a right coracoid presented in dorsal view (Fig. 2A). The bone is elongate and slightly crushed. The proximal head is notably enlarged laterally to form the articular glenoid. Medially, the upper part of the sutural surface with the scapula is clearly visible. Posteriorly to the proximal head, the main body of the bone is thin and was probably cylindrical before crushing. Distally, the coracoid expands into a dorsoventrally flattened blade that is characteristic of many turtles. Its posterior margin is broken. The bone may have been concave dorsally but this could be the result of deformation.

\section{Plastron}

BMNH R5320 is the only turtle shell bone from the Stonesfield Slate. This is a plastron fragment (hyo- or hypoplastron) probably of the bridge area (Fig. 2B). Three spiny projections are present like those that can be found in embryonic or juvenile individuals or in turtles that do not have a fully ossified shell at adult size. The size of the specimen (40 $\mathrm{mm}$ in maximum length) indicates that it does not belong to a hatchling turtle, but it may have belonged to a young individual.

\section{First vertebral scale}

BMNH 37218b (Fig. 3A, B), OUMNH J77375 + J77376 (Fig. 3C, D; See also Phillips, 1871: fig. 41.10-11, p. 182) and OUMNH 177377 (Fig. 3E) are interpreted as first
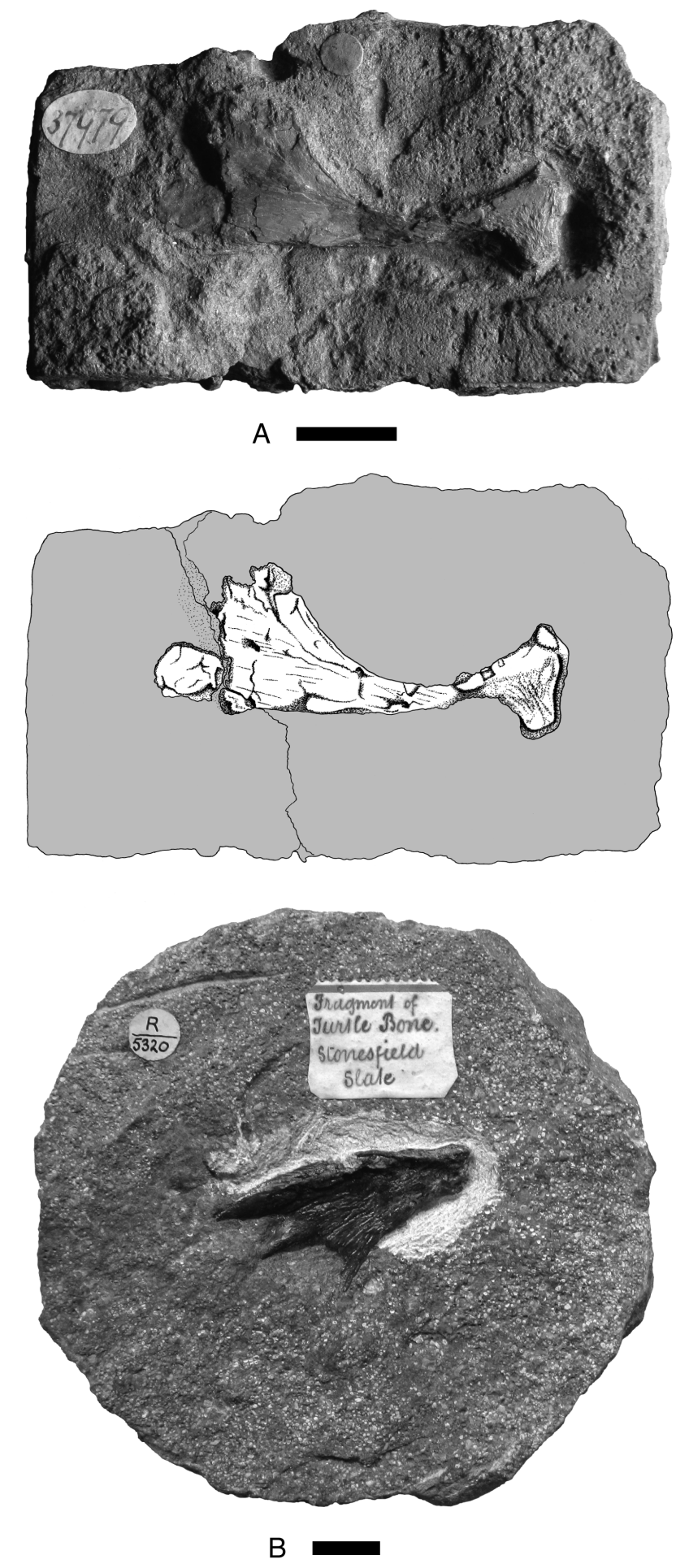

Figure 2 - Turtle bones from the Stonesfield Slate, middle Bathonian. A, BMNH 37979, right coracoid in dorsal view (proximal to the right) figured in Mackie (1863); B, BMNH R5320, plastron fragment (hyo- or hypoplastron) probably from the bridge area. Scale bars: $10 \mathrm{~mm}$.

vertebrals because of their symmetrical, pentagonal shape and their concave posterior margin. The bilateral symmetry is underlined by a strong medial keel that is stronger anteriorly and ends abruptly just before 
reaching the posterior margin of the scale. These scales are almost twice as wide as they are long. It is likely that the second vertebral overlapped the first, as suggested by the presence of a smooth triangular area on the posterior part of the first vertebral and by the disappearance of the medial keel just anterior to this area (Fig. 3C, D). The anterior margin of the first vertebral is convex and longer than the posterior margin. The long lateral margin faces posterolaterally and contacts the first pleural. On BMNH $37218 b$, growth rings are poorly preserved in some areas of the scale. A few anteriorly radiating ridges are present on the anteromedial part of the scale. On OUMNH 777375 + J77376, growth rings and radiating ridges are well

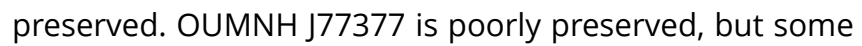
anteriorly radiating ridges are still visible.

\section{Second vertebral scale}

BMNH 37218 (Fig. 3F, G), OUMNH 377378 (Fig. 3H) and OUMNH J37067 (Fig. 3I) are interpreted as second vertebrals because of their symmetrical, hexagonal shape and their anterior margin shorter than the posterior margin (generally, vertebrals 2-4 are hexagonal in outline and differ from each other in the relative development of their anterior and posterior margins). These scales have a straight or slightly concave anterior margin and straight posterior margin. They are twice as wide as long (OUMNH $\mathrm{j} 77378$ is incomplete) and have a medial keel. The anterolateral margin contacts the posteromedial margin of the first pleural and faces anterolaterally. The posterolateral margin contacts the anteromedial margin of the second pleural and extends parallel to the anteroposterior axis of the scale. The anterolateral margin is slightly shorter than the posterolateral one. The medial keel protrudes anteriorly from the anterior margin of the scale. The posterior margin presents a medial emargination that probably corresponds to the anterior protrusion of the medial keel of the third vertebral (see below). On BMNH 37218, growth rings are only slightly apparent medially but are still well defined laterally. Some rings are deeply marked but, between those, thinner rings are often present. The spacing between major growth rings is irregular. A few poorly defined anteriorly radiating ridges are apparent laterally. On OUMNH J7378, growth rings are better preserved, no intercalated thin rings are present, and the spacing between growth rings is relatively regular. An anteriorly radiating pattern covers the whole surface of the scale. On OUMNH J37067, the presence of the medial ridge is uncertain and the majority of growth rings are badly marked (this specimen is poorly preserved). A few anteriorly radiating ridges are present on the anteromedial and posterolateral portion of this specimen.

\section{Third vertebral scale}

BMNH 37218a (Fig. 3J) and BMNH R247a (Fig. 3K) are interpreted as third vertebrals because of their symmetrical, hexagonal shape and their anterior and posterior margins equal in length. Both specimens exhibit a medial keel that is wider and more pronounced anteriorly. The scale is twice as wide as long with substraight anterior and posterior margins. The medial keel protrudes anteriorly from the anterior margin of the scale, whereas a slight medial emargination of the posterior margin probably corresponds to the anterior protrusion of the fourth vertebral. Both lateral margins are oblique with respect to the anteroposterior axis: the anterolateral margin contacts the posteromedial margin of the second pleural, whereas the posterolateral margin contacts the anteromedial margin of the third pleural. The two lateral margins are equal in length. The surface ornamentation of BMNH 37218a is poorly preserved, but growth rings are still well preserved on BMNH R247a. On the latter, thinner (less marked) rings are intercalated between the rather regularly spaced major rings. No radiating pattern is observable, but it should be noted that these specimens are less well preserved than the previously described scales.

\section{Fourth vertebral scale}

BMNH R247 (Fig. 3L, M) is interpreted as a fourth vertebral because of its (original) symmetrical, hexagonal shape and its anterior margin wider than the posterior margin. The right side of the scale and the former emplacement of the embryonic scale are missing. The anterior part of the medial keel is visible on the broken side of the scale. The anterior margin is slightly convex, whereas the posterior margin is slightly concave. Both lateral margins are oblique with respect to the anteroposterior axis: the anterolateral margin contacts the posteromedial margin of the third pleural, whereas the posterolateral margin contacts the anteromedial margin of the fourth pleural. The anterolateral margin is notably shorter than the posterolateral margin. The original scale was approximately twice as wide as long. Due to the preservation, it is unclear whether or not the medial keel protrudes anteriorly, but since a slight medial emargination is present on the posterior margin of the third vertebral (see above) it is probable that it did. Growth rings are relatively well defined and thinner rings are often intercalated between major rings. The spacing between major growth rings is irregular. A pattern of anteriorly radiating ridges is present. 


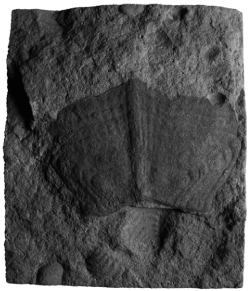

A

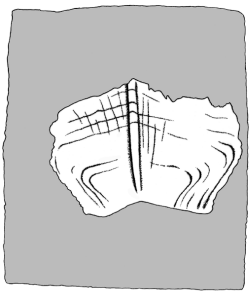

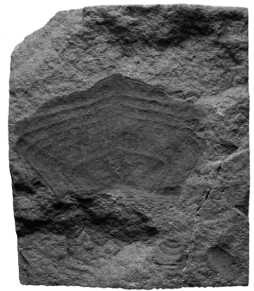

B

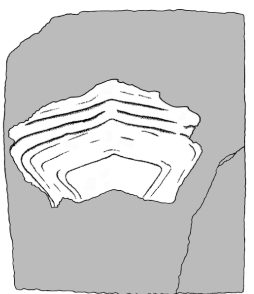

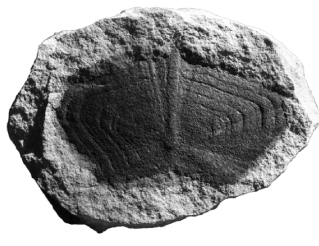

C

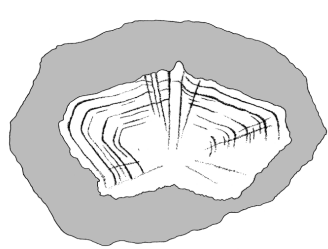

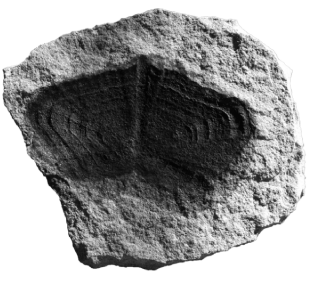

D

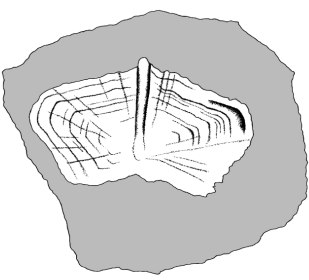

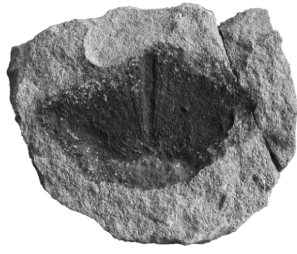

E

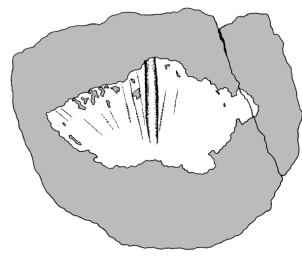

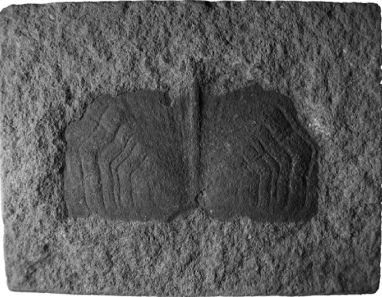

F
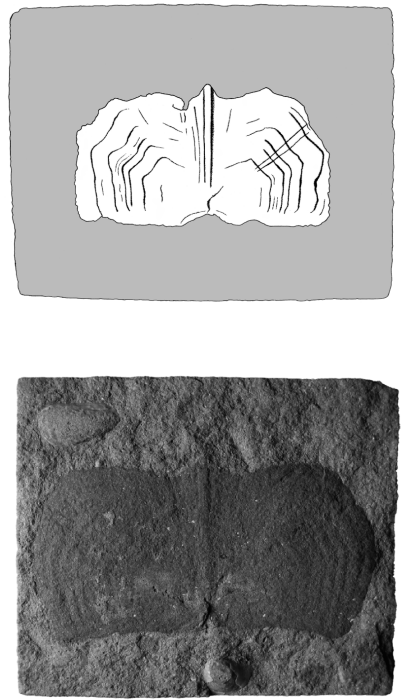

J

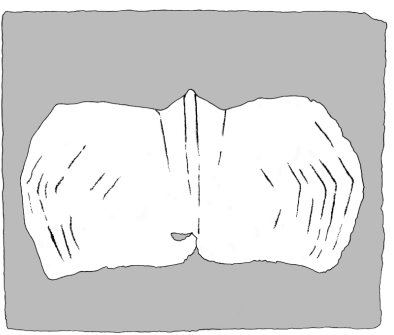

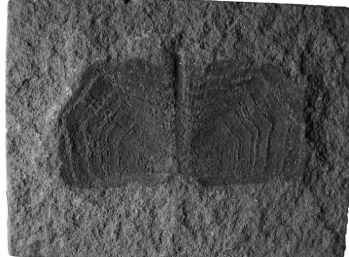

G
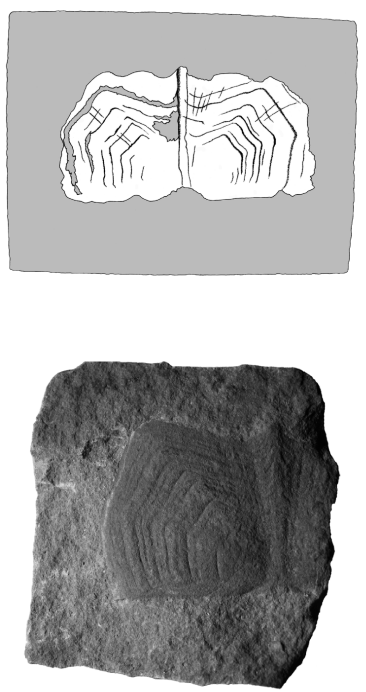

$\mathrm{K}=$

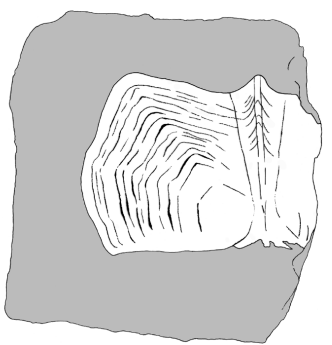

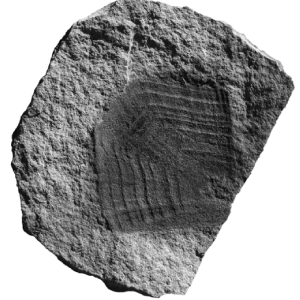

$\mathrm{H}$
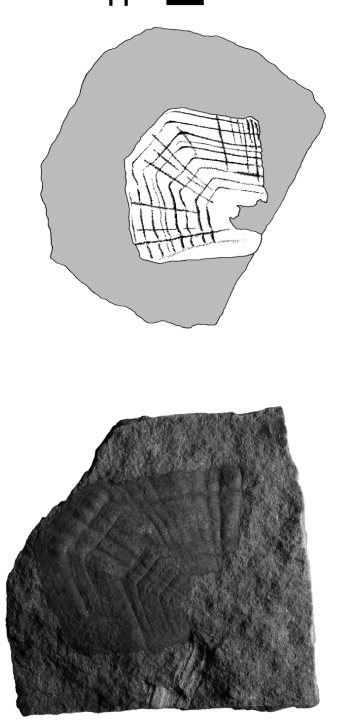

L

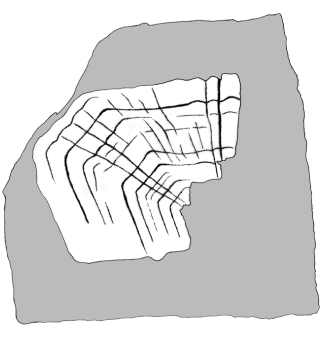

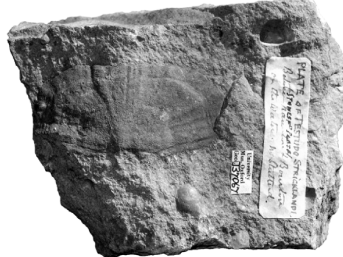

$1=$
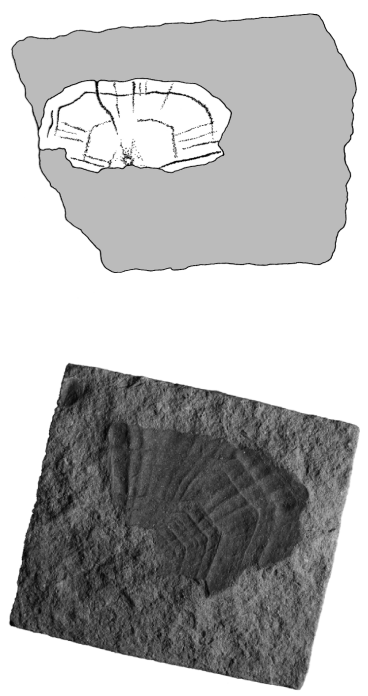

M

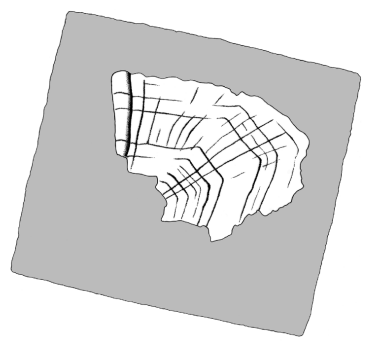

Figure 3 - First to fourth vertebral scales, Stonesfield Slate, middle Bathonian. First vertebral: A-E; Second vertebral: F-I; Third vertebral: J, K; Fourth vertebral: L, M; A, B, BMNH 37218b, almost complete first vertebral (B is the external mould); C, D, OUMNH J77375 + J77376, complete first vertebral ( $D$ is the external mould OUMNH J77376) figured by Phillips (1871); $E$, OUMNH J77377, badly preserved external mould of a first vertebral; F, G, BMNH 37218, complete second vertebral (G is the external mould); H, OUMNH J77378, external mould of the right side of a second vertebral; I, OUMNH J37067, badly preserved small second vertebral; J, BMNH 37218a, complete third vertebral; K, BMNH R247a, left half of a third vertebral; L, M, BMNH R247, left side of a fourth vertebral (M is the external mould). Scale bars: $10 \mathrm{~mm}$. 


\section{Fifth vertebral scale}

OUMNH J40407 (Fig. 4A) and BMNH 39198a (Fig. 4B) are interpreted as fifth vertebrals because of their symmetrical, pentagonal shape and their convex posterior margin. OUMNH J40407 has a well-developed medial keel that is wider anteriorly than posteriorly. On BMNH 39198a, an inflexion present on each growth ring near to the broken side of the scale indicates the presence of a keel although this one is not apparent on the specimen (compare with OUMNH J40407). For both specimens, both the anterior and posterior margins are convex, which differs from the condition in other vertebrals. The anterior margin contacts the posterior margin of the fourth vertebral. The long and arched posterior part of the scale in fact presents two separate margins that correspond to the contact with the two last marginals (probably eleventh and twelfth) at the posterior end of the carapace. The short lateral margin faces anterolaterally and corresponds to the contact with the posteromedial margin of the fourth pleural. The scale is wider than long, but proportionally less wide than vertebrals 2-4. Growth rings are well preserved on OUMNH J40407, although only slightly defined in some areas. The spacing between major growth rings is irregular and a few anteriorly radiating ridges are present anteromedially. By comparison, only major growth rings are preserved on BMNH 39198a and no trace of a radiating pattern is present.

\section{Pleural scales}

BMNH R247b (Fig. 4C, D) is interpreted as a right third pleural because of its non-symmetrical, squarish shape, its straight anterior and posterior margins, its oblique medial margins, and its short posteromedial margin. The scale is slightly longer than wide. The anterior margin is as long as the posterior. On the arched lateral margin, three distinct contacts corresponding to three different marginals can be observed. Growth rings are well

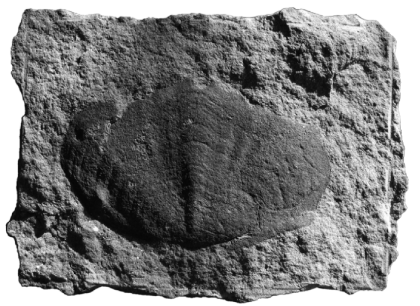

A
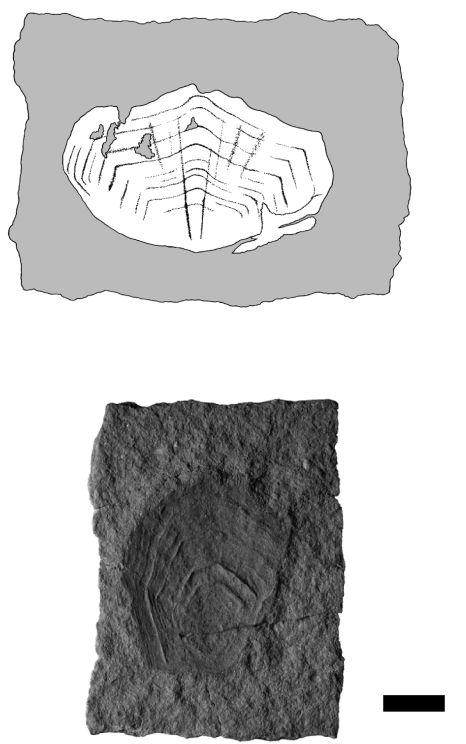

$E_{1}$
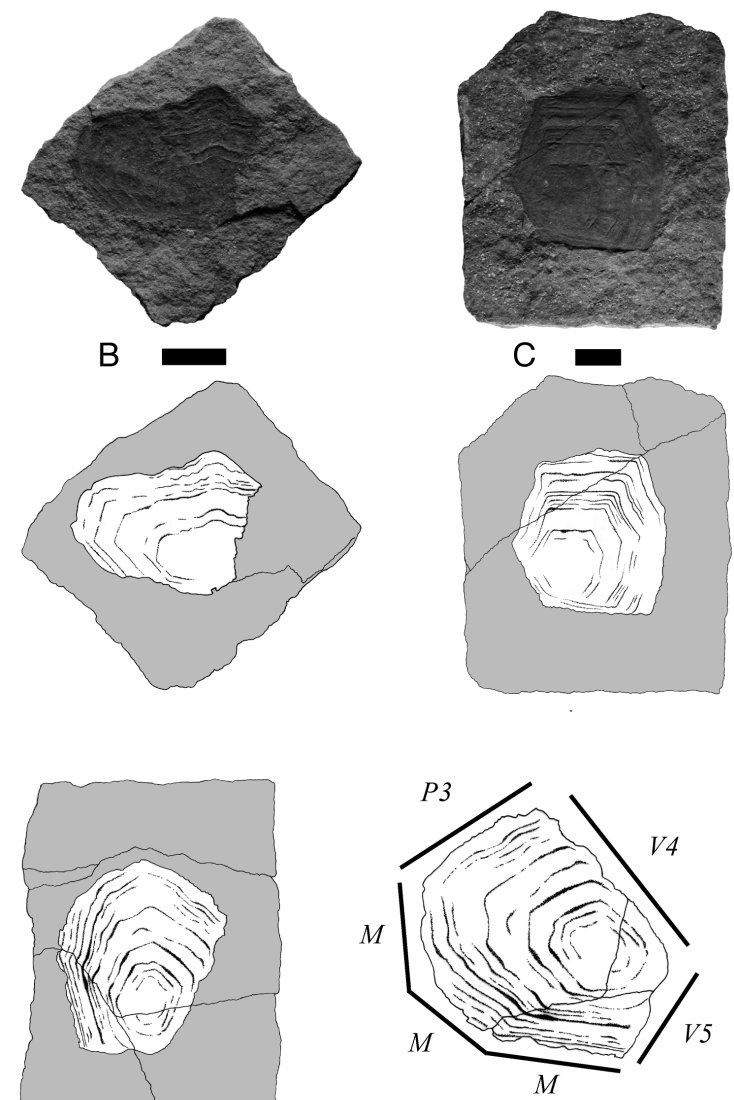

$\mathrm{E}_{2}$

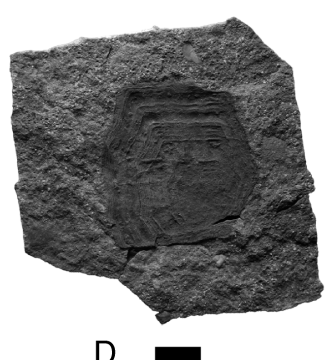

D
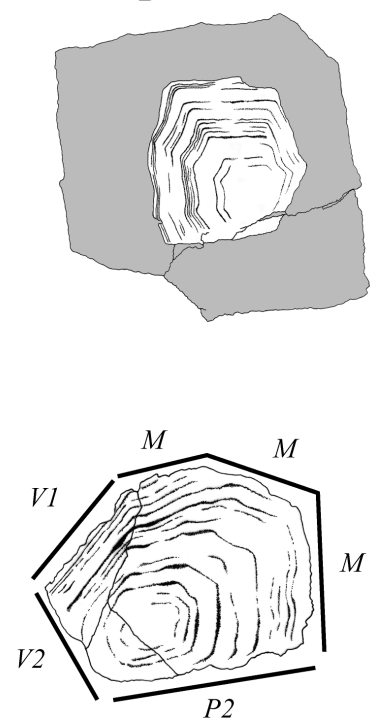

$\mathrm{E}_{3}$

Figure 4 - Fifth vertebral and pleural scales, Stonesfield Slate, middle Bathonian. Fifth vertebral: A, B; Pleural scales: C-E; A, OUMNH J40407, complete fifth vertebral; B, BMNH 39198a, external mould of the right side of a fifth vertebral; C, D, BMNH R247b, complete right third pleural (D is the external mould); $E, B M N H 39198$, external mould of an almost complete scale (E1, non oriented) which can be interpreted either as a right fourth pleural (E2, preferred hypothesis) or as a left first pleural (E3) [the specimen is an external mould and needs to be reversed to retrieve the normal orientation]. Abbreviations: M, marginal scale; P, pleural scale; $V$, vertebral scale. Scale bars: $10 \mathrm{~mm}$. 
preserved, especially on the external mould. Major rings are irregularly spaced and up to three or four less pronounced rings can be seen between some of them. There is no trace of radiating ridges on the scale.

BMNH 39198 (Fig. 4E1) is interpreted as a first or fourth pleural because of its non-symmetrical and irregular pentagonal shape. The original outline of the scale, revealed by growth rings, allows two possible interpretations of this specimen: a right fourth pleural (Fig. 4E2) or a left first pleural (Fig. 4E3). The following observations weaken the second hypothesis: first pleurals are usually more elongate; growth rate should have been greater anteriorly; and the posterior margin that contacts the second pleural should be sub-perpendicular to the anteroposterior axis of the scale. Consequently, we favour an interpretation of BMNH 39198 as a right fourth pleural. The scale is longer than wide. The anteromedial margin (that contacts the posterolateral margin of the fourth vertebral) is damaged and consequently the anterior margin (that contacts the posterior margin of the third pleural) appears shorter than it was originally. The short posteromedial margin corresponds to the contact with the lateral margin of the fifth vertebral. The lateral margin is divided into three parts corresponding to the contact with three different marginals. Growth rings are relatively well preserved. Major rings are irregularly spaced. Few less pronounced rings are present but difficult to distinguish. There is no radiating pattern on the scale.

\section{Comparison}

It is difficult to compare the turtle scales from the Stonesfield Slate with other taxa because no directly comparable material (i.e., fossil epidermal scales) is known. When describing bony shells, systematists can only access information on the general outlines of scales and mainly use their relative sizes for diagnostic purposes. At Stonesfield, although they match each other fairly well (Fig. 5A), the scales are isolated and obviously pertain to different individuals: they show different growth rates, different sizes and there is no indication that all of the scales come from the same stratigraphical horizon. So that the relative sizes of the Stonesfield scales cannot be assess. However, the detailed description provided herein enables some comparisons to be made.

A tentative reconstruction of the carapace of the Stonesfield turtle is provided in Figure 5B. An important characteristic of this turtle is that vertebrals are wider than long, whereas pleurals are slightly longer than wide. This is a rather primitive scheme commonly found in stem turtles and basal crown-group turtles. More derived

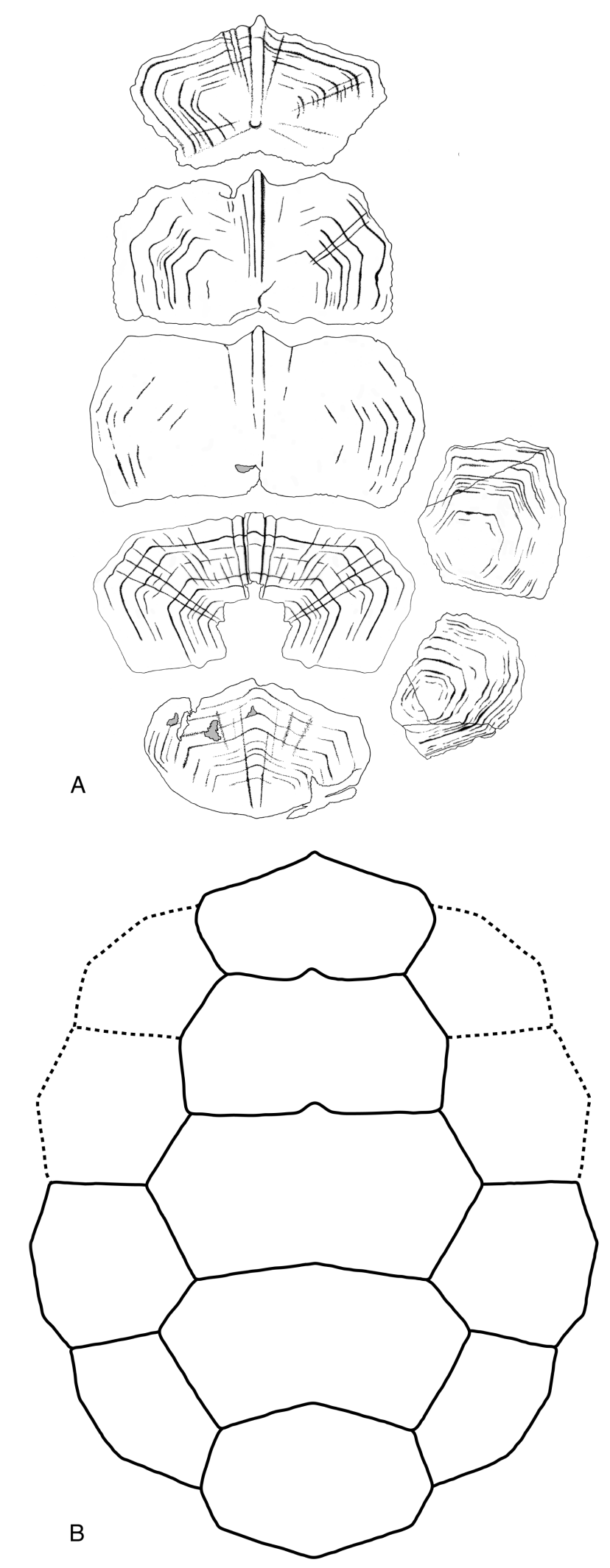

Figure 5 - Reconstruction of the Stonesfield turtle, middle Bathonian. A, Reconstruction based on available specimens (note that these specimens are not from the same individuals nor at the same scale); B, Proposed reconstruction of the carapace of the Stonesfield turtle. The morphology of the first and second pleural (dashed lines) can be deduced from that of neighbouring scales. Marginals are unknown at Stonesfield and therefore are not represented on the present reconstruction. 
turtles tend to have vertebrals that are longer than wide and pleurals that are wider than long.

Among turtles with wide vertebrals and narrow pleurals, the Stonesfield turtle more closely resembles the stem turtles Kayentachelys aprix (Gaffney et al. 1987), Indochelys spatulata (Datta et al. 2000), Heckerochelys romani (Sukhanov 2006) and Kallokibotion bajazidi (Gaffney \& Meylan 1992), the panpleurodire Notoemys laticentralis (Fernandez \& Fuente 1994; Lapparent de Broin et al. 2007), and the pleurosternid Dinochelys whitei (Gaffney 1979; Brinkman et al. 2000). The aforementioned species share the following features with the Stonesfield turtle: large vertebral 1 with a convex anterior margin that is at least as wide as the posterior margin; vertebral 2 with a posterolateral margin more or less parallel to the anteroposterior axis of the shell; vertebral 4 with a significantly short anterolateral margin; vertebral 5 wider than long with an anterior margin as wide as the posterior margin. The Stonesfield turtle differs from each of these species by several of its characters. Vertebrals 2-4 of Kayentachelys and Indochelys are wider than those of the Stonesfield turtle, whereas they are narrower in Kallokibotion. In Kayentachelys, vertebral 1 is at least 3 times wider than long and three distinct margins anteriorly (one for each marginal 1 and one for the cervical scale). Vertebral 1 of Dinochelys and Notoemys is also wider than in the Stonesfield turtle. In Kallokibotion, vertebral 1 is narrower and more elongated than that of the Stonesfield turtle and its lateral margin is parallel to the anteroposterior axis of the shell. In Notoemys, the lateral margin of vertebral 1 are also parallel to the anteroposterior axis of the shell and all intervertebral sulci are straight. Dinochelys also has straight intervertebral sulci. Heckerochelys differs from the Stonesfield turtle in having a longer vertebral 2, vertebral 3 with strongly concave posterior margin and vertebral 4 with only one lateral margin.

Concerning the scale ornamentation, none of the aforementioned species is known to have one, although it is possible that scale ornamentation does not always leave a trace on the bone plate of the shell. One can notice that the anterior margin of vertebrals 2-5 of Kayentachelys presents a well-defined, short medial protrusion similar to that of the Stonesfield turtle. Other turtles known to have a scale ornamentation of anteriorly radiating ridges on the vertebrals (e.g., Proganochelys, Platychelys, Euryaspis, Desmemys, some plesiochelyids and chengyuchelyids) do not match the morphology of the Stonesfield turtle.

Romer (1956, 1966) and Bergounioux (1955) referred the turtle from Stonesfield to the Pleurosternidae. Pleurosternon bullockii, Glyptops plicatulus and 'Glyptops' typocardium (Gaffney 1979; Milner 2004) all have vertebrals that are reduced in width and pleurals wider than long. Among pleurosternids, only the Late Jurassic Dinochelys whitei has a scale pattern similar to that of the Stonesfield turtle. However, as it is also true for other species ranging from Early Jurassic stem turtles to basal panpleurodires (see above), one can only assume that this scale pattern is plesiomorphic. In other words, a referral to the pleurosternids is not better supported than a referral to the stem Testudines or the Panpleurodira in the current state of knowledge.

\section{Taphonomy}

The preservation of turtle epidermal scales is rather uncommon in the fossil record. We are aware of only two other cases: a shell fragment from the Pleistocene of NE Thailand (J. Claude personal observation) and a shell of Neurankylus from the early Paleocene of New Mexico (Sullivan et al. 1988). In the later case, the scales are preserved on approximately $85 \%$ of the carapace, are rich in iron and manganese, and are apparently preserved with the original colour pattern (Sullivan et al. 1988: fig. 3). In both cases, the scales are preserved as a thin layer on the surface the bony shell, but the Stonesfield specimens are the only known example of isolated scales in the fossil record. Isolated epidermal scales can result from two processes: shedding during growth or post mortem disarticulation.

To our knowledge, no detailed studies of the posthatching development of shell scales have been published. In a recent review on the use of growth rings to estimate turtle age, Wilson et al. (2003) discuss this lack of literature on epidermal scale growth. Two patterns are seen in extant turtles (Wilson et al. 2003: fig. 1). In some turtles (e.g., Terrapene carolina), scales do not shed and old layers are retained on the external surface of new ones. In such cases, growth rings correspond to the superposition of successively larger and younger scales. Such scales become thicker with age, although old layers are often progressively worn by abrasion. In other turtles (e.g., Trachemys, Orlitia, Chrysemys), the old scale is shed while the new one grows beneath it. Although the mechanism is not yet understood, the old layers leave an impression, corresponding to the growth ring, on the new scale. Shed keratinous scale layers are thin, translucent and flexible, and are consequently unlikely to fossilise. Moreover, we were unable to find any reference mentioning the persistence of shed scale layers in the environment, which might suggest that they are quickly destroyed after shedding. 
The isolated nature of Stonesfield scales probably results from disarticulation rather than shedding: shed scales are thinner and more fragile than complete scales, and are therefore less likely to fossilise. Moreover, shed scales would probably not display such marked growth rings. Indeed, extant shedding turtles tend to have smooth epidermal scales with poorly developed rings.

Turtle taphonomy is poorly studied and the few available studies deal primarily with bones, which is little help with the Stonesfield material. Frustratingly, studies on extant species often fail to mention epidermal scales at all (see Brand et al. 2003 for a more detailed review). However, among these neontological studies, Bourn \& Coe (1979) reported the disarticulation sequence of Geochelone gigantea (the Aldabra tortoise) and stated that at some point in the sequence, scales detach themselves from each other and from the bony layer before falling. Dodd (1995) documented the disarticulation patterns of 80 turtle carcasses, representing three families (emydids, testudinids and trionychids), in a terrestrial sandhill habitat in north Florida. As noted by Bourn \& Coe (1979), Dodd (1995) also observed that the keratinous scales of emydids and testudinids eventually detached themselves individually from the shell (trionychids have no scales but a leathery skin covering the shell). He noted that the vertebrals and pleurals generally detach simultaneously, or the former closely followed by the latter. Marginals are often the first group to detach, although they persist longer than the vertebrals and pleurals in the testudinid Gopherus polyphemus. Dodd (1995: 383) observed that disarticulated scales may remain close to the carcass for an extended period. Brand et al. (2003) carried out an experimental study to compare the disarticulation processes for the common slider turtle (Trachemys scripta) in different environments. They observed that separation between scales and shell bones occurred at the same time as shell disarticulation. Unfortunately, the detached elements were removed immediately from the experimental area so there was no estimation of the time that disarticulated scales could remain in the environment.

Thus, taphonomic studies on turtles have not so far explained the fate of scales once detached or shed. For example, it is unknown how long keratinous scales can remain in the environment, how they are affected by transport or what conditions may be conducive to their preservation. The Stonesfield specimens are the only isolated fossil turtle scales known to date, though it is possible that others exist and have been misinterpreted or remain unrecognised and undescribed. The preservation of isolated keratinous elements is unusual in the fossil record and probably requires particular burial environments and transport conditions. In addition, there are currently no detailed taphonomical studies of the Stonesfield biota in general that could explained the preservation of these scales, although similarities of preservation with the plant remains from the same locality are striking (Cleal \& Rees 2003).

\section{Conclusions}

A reassessment of the available material from the Middle Jurassic Stonesfield Slate shows that the turtle previously known as Protochelys Lydekker, 1889 cannot be properly diagnosed from other taxa nor placed within a phylogenetic framework. Protochelys blakii (Mackie, 1863) is consequently considered nomen dubium, until more evidences are found. This situation is a direct consequence of the nature of the preserved specimens.

The Stonesfield turtle presents a plesiomorphic scale pattern with vertebrals that are twice as wide as long, pleurals that are reduced in width and a fifth vertebral with an anterior margin as wide as its posterior margin. These features are commonly found in stem turtles and some basal crown-group turtles. Any phylogenetic assignment of this turtle is then difficult to achieve, although the combination of these primitive features suggests a basal phylogenetic position.

Although the Stonesfield turtle scales have a limited systematic value, they are important in terms of taphonomy. These remains are the only known example of isolated fossil turtle scales. The Stonesfield scales probably result from disarticulation processes as such scales are thicker, more resistant and more likely to preserve well-developed ornamentation (growth rings and radiating ridges) than shed scale layers. Now that fossil turtle scales have been described and figured extensively for the first time, it will be easier for future workers to recognise them. In the same time, this study also enlightens the fact that taphonomic literature generally overlooks the fate of shed scale layers and disarticulated scales. This should be taken into consideration by future taphonomic studies on turtles.

\section{Acknowledgements}

The authors thank Sandra Chapman and Angela Milner (Natural History Museum, London, UK), and Paul Jeffery (Oxford Museum of Natural History, Oxford, UK) for access to collections in their care. The help from Andrew Ross (Natural History Museum, London, UK) and Lionel Cavin (Muséum d'Histoire Naturelle, Genève, Switzerland) at the beginning of the study was deeply appreciated. Our gratitude also goes to Paul Barrett (Natural History Museum, London, UK), Guillaume Billet 
and Peggy Vincent (both at the Muséum National d'Histoire Naturelle, Paris, France) for their comments on earlier versions of the manuscript. Igor Danilov and an anonymous reviewer provided helpful comments. This is publication ISEM 2008-019 of J.C.

\section{References}

Anquetin J. 2007. - A new (stem?) turtle from the Middle Jurassic of Skye, Scotland. Journal of Vertebrate Paleontology 27(3): 41A.

Aston M. 1974. - Stonesfield Slate. Oxfordshire County Council, Department of Museum Services, Publication 5.

Benton M. J. \& Spencer P. S. 1995. - Fossil reptiles of Great Britain. Chapman and Hall, London, 386 p.

Bergounioux F. M. 1955. - Testudinata, in Piveteau J. (ed.), Traité de Paléontologie, Volume 5. Masson et Cie, Paris: 487-544.

Blake C. C. 1863. - On chelonian scutes from the Stonesfield Slate. The Geologist 6: 183-184.

Boneham B. F. W. \& Wyatt R. J. 1993. - The stratigraphical position of the Middle Jurassic (Bathonian) Stonesfield Slate of Stonesfield, Oxfordshire, UK. Proceedings of the Geologists' Association 104(2): 123-136.

Bourn D. \& Coe M. J. 1979. - Features of tortoise mortality and decomposition on Aldabra. Philosophical Transactions of the Royal Society of London, Series B, Biological Science 286: 189-193.

Brand L. R., Hussey M. \& Taylor J. 2003. - Taphonomy of freshwater turtles: decay and disarticulation in controlled experiments. Journal of Taphonomy 1(4): 233-245.

Brinkman D. B., Stadtman K. \& Smith D. 2000. - New material of Dinochelys whitei Gaffney, 1979, from the Dry Mesa Quarry (Morrison Formation, Jurassic) of Colorado. Journal of Vertebrate Paleontology 20(2): 269-274.

Buckland W. 1824. - Notice on the Megalosaurus, or great fossil lizard of Stonesfield. Transactions of the Geological Society of London 1(2): 390-396.

Cleal C. J. \& Rees P. M. 2003. - The Middle Jurassic flora from Stonesfield, Oxfordshire, UK. Palaeontology 46(4): 739-801.

Datta P. M., Manna P., Ghosh S. C. \& Das D. P. 2000. The first Jurassic turtle from India. Palaeontology 43(1): 99-109.
Dodd C. K. Jr. 1995. - Disarticulation of turtle shells in North-central Florida: how long does a shell remain in the woods? American Midland Naturalist 134: 378-387.

Evans S. E., Barrett P. M., Hilton J., Butler R. J., Jones M. E. H., Liang M.-M., Parish J. C., Rayfield E. J., SigogneauRussell D. \& Underwood C. J. 2006. - The Middle Jurassic vertebrate Assemblage of Skye, Scotland, in Barrett P. M. \& Evans S. E. (eds), Ninth International Symposium on Mesozoic Terrestrial Ecosystems and Biota, Abstracts and Proceedings. The Natural History Museum, London: 36-39.

Evans S. E. \& Milner A. R. 1994. - Middle Jurassic microvertebrate assemblages from the British Isles, in Fraser N. C. \& Sues H.-D. (eds.), In the shadow of the dinosaurs - Early Mesozoic tetrapods. Cambridge University Press, Cambridge: 303-321

Fernandez M. S. \& Fuente M. S. de la. 1994. Redescription and phylogenetic position of Notoemys: the oldest Gondwanian pleurodiran turtle. Neues Jahrbuch für Geologie und Paläontologie, Abhandlungen 193(1): 81-105.

Gaffney E. S. 1979. - The Jurassic turtles of North America. Bulletin of the American Museum of Natural History 162(3): 91-136.

Gaffney E. S., Hutchison J. H., Jenkins F. A. \& Meeker L. J. 1987. - Modern turtle origins: the oldest known cryptodire. Science 237: 289-291.

Gaffney E. S. \& Meylan P. A. 1992. - The Transylvanian turtle, Kallokibotion, a primitive cryptodire of Cretaceous age. American Museum Novitates 3040: 1-37.

Gillham C. 1994. - A fossil turtle (Reptilia: Chelonia) from the Middle Jurassic of Oxfordshire, England. Neues Jahrbuch für Geologie und Paläontologie, Monatshefte 1994(10): 581-596.

Joyce W. G., Parham J. F. \& Gauthier J. A. 2004. Developing a protocol for the conversion of rank-based taxon names to phylogenetically defined clade names, as exemplified by turtles. Journal of Paleontology 78(5): 989-1013.

Klein I. T. 1760. - Klassification und kurze Geschichte der Vierfüßigen Thiere (translation by FD Behn). Jonas Schmidt, Lübeck.

Lapparent de Broin F. de, Fuente M. S. de la \& Fernandez M. S. 2007. - Notoemys laticentralis (Chelonii, Pleurodira), Late Jurassic of Argentina: new examination of the anatomical structures and comparisons. Revue de Paléobiologie 26(2): 99-136.

Lydekker R. 1889. - Catalogue of the fossil reptilia and amphibia in the British Museum (Natural History) - 
Part III. The Order Chelonia. Trustees of the British Museum, London, 239 p.

Mackie S. J. 1863. - Turtles in the Stonesfield Slate. The Geologist 6: 41-43.

Milner A. R. 2004. - The turtles of the Purbeck Limestone Group of Dorset, Southern England. Palaeontology 47(6): 1441-1467.

Owen R. 1842. - Report on British fossil reptiles, part 2. Report for the British Association for the Advancement of Science, 11(Plymouth 1841): 60-204.

Phillips J. 1871. - Geology of Oxford and the valley of the Thames. Clarendon Press, Oxford: 523 p.

Romer A. S. 1956. - Osteology of the Reptiles. University of Chicago Press, Chicago, 772 p.

Romer A. S. 1966. - Vertebrate Paleontology, 3rd edition. University of Chicago Press, Chicago, 468 p.

Rowe T. 1999. - At the roots of the mammalian family tree. Nature 398: 283-284.

Scheyer T. M. \& Anquetin J. 2008. - Bone histology of the Middle Jurassic turtle shell remains from Kirtlington, Oxfordshire, England. Lethaia 41(1): 85-96.

Shute C. H. \& Cleal C. J. 1987. - Palaeobotany in museums. Geological Curator 4: 553-559.

Sukhanov V. B. 2006. - An archaic turtle, Heckerochelys romani gen. et sp. nov., from the Middle Jurassic of Moscow region, Russia, in Danilov I. G. \& Parham J. F. (eds.), Fossil Turtle Research, Volume 1, Russian Journal of Herpetology 13(Suppl.): 112-118.

Sullivan R. M., Lucas S. G., Hunt A. P. \& Fritts T. H. 1988. - Color pattern on the selmacryptodiran turtle Neurankylus from the early Paleocene (Puercan) of the San Juan Basin, New Mexico. Contributions in Science, Natural History Museum of Los Angeles County 401: 1-9.

Torrens H. S. 1980. - Bathonian correlation chart, in Cope J. C. W. (ed.), A correlation of Jurassic rocks in the British Isles, Part 2. Geological Society, London, Special Report 15: 21-45.

Wilson D. S., Tracy C. R. \& Tracy C. R. 2003. Estimating age of turtles from growth rings: a critical evaluation of the technique. Herpetologica 59(2): 178-194.

Zangerl R. 1969. - The turtle shell, in Gans C., Bellairs A. \& Parsons T. S. (eds.), Biology of the reptilia, Volume 1. Academic Press, London and New York: 311-339. 